\title{
Refractory EBV-Related Lymphoma
}

National Cancer Institute

\section{Source}

National Cancer Institute. Refractory EBV-Related Lymphoma. NCI Thesaurus. Code C160149.

EBV-related lymphoma that is resistant to treatment. 